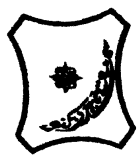

Bayero Journal of Pure and Applied Sciences, 4(2): 107 - 121

Received: November, 2018

Accepted: December, 2018

ISSN $2006-6996$

\title{
RISK FACTORS AND MODE OF TRANSMISSION OF TOXOPLASMOSIS IN NIGERIA: A REVIEW
}

\author{
Sharif, A. A. ${ }^{1}$, Aliyu, M., ${ }^{1}$ Yusuf, M. A., ${ }^{1}$ Getso, M. $I^{1}$, Yahaya, H., ${ }^{2 *}$ Bala, J. A., ${ }^{2}$ \\ Yusuf, $I_{.}{ }^{3}$ and Wana, M. N. ${ }^{4}$ \\ ${ }^{1}$ Dept of Medical Microbiology and Parasitology, Faculty of Clinical Sciences, Bayero University Kano. \\ ${ }^{2}$ Department of Medical Laboratory Science, Faculty of Allied Medical Sciences, Bayero University Kano. \\ ${ }^{3}$ Department of Microbiology, Faculty of Science, Bayero University Kano. \\ ${ }^{4}$ Department of Microbiology, Faculty of Science, Abubakar Tafawa Balewa University, Bauchi, Nigeria. \\ *Corresponding author: hyahaya.mls@buk.edu.ng; $+601151255260 ;+2348034242923$
}

\begin{abstract}
Toxoplasmosis is a cosmopolitan infection caused by an obligate intracellular protozoan, Toxoplasma gondii. The parasite was described as the most successful having full potentials to be transmitted through various routes from contamination of the environment and food substances to continuous spread as tissue cyst in meat, among its intermediate host, bypassing its sexual stage of life cycle in its definitive host. Relevant English databases were searched for the prevalence studies conducted in Nigeria. In this review, we identified the various ways through which the infection can be spread within human population as reported by various studies in Nigeria.

Keywords: cosmopolitan, environment, intracellular, protozoan, toxoplasmosis
\end{abstract}

\section{INTRODUCTION}

Toxoplasma gondii is an obligate intracellular protozoon in the Phylum Apicomplexa. It is ubiquitous that was reported to have infected more than $1 / 3$ of human population globally (Foroutan and Ghaffarifar, 2018). Infection with T. gondii in human is a risk of developing retinal damage, mental disorders, obstetrics disorders and birth defects. Perhaps, because of its wide range of intermediate host and its potential to contaminate food substances and the environment, one cannot easily pinpoint a mode through which a ubiquitous organism like $T$. gondii is transmitted. The parasite can be transmitted in form of a tissue cyst, as a sporulated oocyst and inform of a tachyzoite. Whichever way, transmission and distribution of this zoonotic, obligate intracellular parasite depends on many factors, some of which are; climatic condition of the area, availability of viable infective stage of the parasite in the area, route of transmission of infective stage, personal eating habit and hygiene, mingling with and consumption of animals that serve as definitive or intermediate hosts (Meerbug et al., 2009; Yan et al., 2016).

In Nigeria, most of the prevalence studies tried to find out the associated risk factors through which a mode of transmission can easily be predicted. Ohiolei and Isaac (2016), according to their 10 years review on toxoplasmosis in Nigeria, they reported that North-West and South-West geopolitical zones of the country have the highest prevalence of the infection compared to other geopolitical zones. More so, the prevalence of the infection from South-South and South East geo-political zones were reported to be low according to the pooled study reports from 2005-2015 as indicated by the study. In contrary, Oboro et al. (2016) reported $65.6 \%$ seropositivity among pregnant women in Port-Harcourt, South-South, Nigeria. It has been reported in several literatures that the prevalence of toxoplasmosis varies between countries and even within a country and between localities, largely due to differences in environmental conditions, feeding habits and availability of more intermediate and definitive hosts agents (Robert-Gangneux and Darde, 2012). Though with different methodology, both human (pregnant women, HIV infected individuals, women of child bearing age, normal population, school children, abattoir workers, patient with cancer, patients with mental disorders e.t.c) and other mammal/birds (Goat, Sheep, Horse, Camel, Cats, Chicken, Dogs, Cattle, Pigs, e.t.c) 
that serve as intermediate hosts as well as the definitive hosts were screen across all the six geopolitical zones in Nigeria with varying prevalence from 1960 to date (Ohiolei and Isaac, 2016). These findings prompted the reviewers to examine, keenly, the mode of transmission of $T$. gondii in Nigeria by recognizing the major risk factors available in the literature.

\section{Transmission through the Oocyst Cat ownership and Soil}

Oocyst is an infective stage in T. gondii infection after undergoing sporulation in the environment. It is a product of sexual stage of the life cycle which takes place in a cat. Domestic cats pass large number of oocysts along with faces after ingesting at least one tissue cyst. The number of the oocyst passed can be up to millions (Hill and Dubey, 2002). However, single passage of millions of oocysts in to the environment results in contamination due to spread, mechanically, by some hosts agents such as (cockroaches, earthworm, flies e.t.c) as well as soil, water and wind and the sporulated oocyst can survive in moist soil at an appropriate condition for many years (Robert -Gangneux and Darde, 2012). Transmission of this environmental stage to human may result due to ingestion of contaminated food items such as fruits, vegetables and water. Contamination of these food items may result from cat faeces or contaminated soil. It was also shown that handling of cat's litters can result in transmission of the oocyst stage because they can sporulate therein and remain infective for two weeks. However, the sporulated oocyst can be killed within few minutes at temperature range between $55^{\circ} \mathrm{C}$ and $60^{\circ} \mathrm{C}$ which can help reduce the burden of transmission through ingestion of vegetables, water and occasionally fruits (Robert-Gangneux and Darde, 2012). DejiAgboola et al. (2011) in a prevalence study conducted on pregnant women in Lagos state, South west Nigeria, reported no seropositivity among the respondents with history of handling cat litter box or had cats in their household. But this contrast other findings in the same area. Okwuzu et al. (2014) reported that "close proximity with cats has a significant association" with toxoplasmosis. Akinbami et al. (2010) reported that $63.6 \%$ out of those respondents that keep pets are seropositive, while $39.5 \%$ of those that do not keep pets are also seropositive. Both studies were conducted in the same region. From South-South region, Oboro et al. (2016) reported $4.2 \%$ seropositivity among the respondents that own cats while $16.5 \%$ seropositivity among those with cats in their neighborhood. A study conducted by Yusuf et al. (2016) in Kano, North-west Nigeria, among pregnant women reported that of all the respondents $64.1 \%$ had contact with cats in their life time while $71.2 \%$ handle cat litters. More so, James et al (2013) reported high seropositivity among those with mental disorders that kept pets. Uttah et al. (2013) reported $45.61 \%$ seropositivity among cat owners in Abuja, North Central Nigeria among three subgroups (Pregnant women, immunocompetent and immunocompromised). The study further stressed that the risk of contracting toxoplasmosis is three times higher among pregnant women that own cats and this is also supported by study from Gombe, North-East Nigeria by Ballah et al. (2017). Ibrahim et al. (2017a) reported 27\% IgM seropositivity among respondent who owns cats with significant association at $P=0.0014$.

The possibility of high rate of transmission through cat ownership or handling their litters is globally debated. Soil has been implicated as the main agent through which oocyst can be transmitted to human, because it harbours the oocyst shed along with the faeces and helps maintain its viability for years depending on the environmental conditions (Yan et al., 2016). For this reason, El-sheikha (2008) had the opinion that direct contact with cats may not be as important as a way of transmission of oocyst because humans continuously meet soil in most of their daily activities. Furthermore, a study by Weigel et al. (1999) reported that contact with contaminated soil may likely be a mechanism through which human infection with $T$. gondii occurs. Dos Santos et al. (2010) in a study conducted in Brazil, reported high number of Toxoplasma oocyst detected in $32 \%$ of school playground and this may be a risk factor for toxoplasmosis in school children because of their possible frequent contact with soil contaminated with oocyst as reported in several studies (Sharif et al., 2010; Gyang et al., 2015). Yohanes et al. (2017) reported $72.4 \%$ seropositivity among pregnant women with history of ingestion of soil.

\section{Water}

Water body can serve as a source of infection with oocyst when contaminated by soil or cats faeces. Water can harbor viable oocyst for a very long time with inherent ability to resist freeing (Yan et al., 2016). Sporulated oocyst can withstand moderately higher temperature in 
water and still viable and has a modified outer shell that strongly resist any effect of chemical disinfectants during water treatment (Dumetre and Darde, 2003). Rainfall also plays a significant role in making the oocyst available for transmission through water body leading to water-borne diseases and through contamination of food items such as vegetables. Following increase in precipitation, river flows also increases, and this takes along, oocyst contaminated soil and other contaminated objects down to the river with some deposited along the coast (Shapiro et al., 2012). Active movement of water along the coast also ensures redistribution of the oocyst to other places that were hitherto not contaminated (Jasper et al., 2013). It is interesting to also note that rain also contributes to the environmental transmission of T. gondii through an:

a. Increase in environment moisture condition suitable for oocyst viability

b. Increase in food substrate supply for most of the intermediate hosts

c. Increase incidence of feline infection by causing more exposure of the definitive host to T. gondii (Afonso et al., 2010; Yan et al., 2016).

In some parts of the world, outbreaks of water borne toxoplasmosis were reported with significant morbidity (Aramini et al., 1999; De Moura et al., 2006). In a study conducted by Ajmal et al. (2013), oocyst of T. gondii was detected in drinking water from municipality, lake, ponds and from water around the farms. In most studies conducted in Nigeria, the prevalence studies reported did not include water source as a risk factor. Study conducted by Ishaku et al. (2009) reported that pregnant women who used well water had higher prevalence at $41.6 \%$ compared to those using piped and packaged water at $25.9 \%$ and $20.8 \%$ respectively. More recently however, Yusuf et al. (2016) reported that $32.2 \%$ of the seropositive subjects among pregnant women had Wells and $35.7 \%$ had pipe borne water as their sources of water. These two studies indicate that water source could be a risk of contracting infection with $T$. gondii. Though, there exists observable difference in both studies, but a clear indication is that even those that rely purely on packaged and or piped borne water source are still at risk. Also reported from a neighboring African country, Ethiopia by Yohanes et al. (2017) that $80.0 \%$ of the respondents utilize wells as their source of drinking water. It was reported that consumptions of contaminated well water surrounded with poor hygienic condition, correlates positively with toxoplasmosis. This was backed by PCR based studies in France and Poland (Villena et al., 2004; Sroka et al., 2010). This may be an important source of oocyst since many depend on wells as their major source of water most of which are not in hygienic condition and not as standard as recommended by World health organization (WHO). In as much as water, from any source can serve as a vehicle for transmitting toxoplasmosis, the estimated $1 / 3$ of global population infected may be an under estimation because of its relevance to humans.

\section{Vegetables and Fruit}

Oocyst contaminated water or soil can cause contamination of food substances such as vegetables and fruits. Human consumption of contaminated fruits and vegetables can lead to toxoplasmosis. Though detection of oocyst on vegetable and fruits are not frequently reported in literatures, Ajmal et al. (2013) reported, through a PCR based detection, a high prevalence of contamination in vegetable $(5.6 \%)$ than Fruit (4\%) and further showed that this contamination is associated with rainfall. Thus, poorly washed vegetable and fruits can act as mechanical vehicle for transmission of toxoplasmosis. In Nigeria, Deji-Agboola et al. (2011) reported that consumption of uncooked vegetable and engaging in farming activities were associated significantly with IgG positivity. More recently also, Ibrahim et al. (2017a) reported $47 \%$ of the respondents that are seropositive, consumed unwashed fruits/vegetable with statistically significant association $(P=0.0001)$. However, a recent finding from South Ethiopia among pregnant women reported that $83.5 \%$ of the respondents with history of ingestion of raw vegetable and fruits are seropositive (Yohanes et al., 2017). Continuous efforts need to be in place to educate people on proper handling and usage of fruits and vegetables before used and this should be included by researchers for evaluation as a risk factor.

\section{Transmission through the Tissue Cyst Contaminated Meat}

Meat from animal sources or birds is at risk of contamination because $T$. gondii infects almost all warm-blooded animals including birds. Tissue cyst stage is a chronic form of the parasite infection stage established at a specific site to which the parasite has high affinity such as the brain, retina, heart, lungs and skeletal muscles (Dubey, 1998). 
Within these organs, the parasite's bradyzoite stage replicate slowly owing to its benign nature and latent infection with potentials of reactivation to its invasive form in a setting of immunosuppression. Thus, storage of animal parts or specific organs should take into cognizance of the cyst's ability to resist extremes of temperatures. It was reported that, depending on the size and thickness of the meat, freezing at a very low temperature, lower than $-12^{\circ} \mathrm{C}$ for 72 hours or more is enough to render the cyst unviable (Dubey and Beattie, 1988). However, though it depends on the time of exposure, high temperature of up to $67^{\circ} \mathrm{C}$ kills the cyst stage within a very short time (Dubey et al., 1990).

Therefore, eating of poorly cooked or raw meat sourced from all the intermediate hosts stands as a greater risk of $T$. gondii transmission which was said to be dependent on the type of meat consumed (Robert-Gangneux and Darde, 2012) and in the USA T. gondii infection is responsible for $24 \%$ of death due to foodborne pathogens (Guo et al., 2015).

Meat consumption in Nigeria was reported to be on the increase (Bénard et al., 2010; Babola et al., 2015). Types of meat and consumption pattern among Nigerians were found to be influenced by the type of preferred meat, income, location, season, quality, taste, processing method and price (Okunlola, 2012; Adetunji and Rauf, 2012). Beef meet was reported by Bobola et al. (2015) to have the higher percentage of meat consumption in Nigeria (71\%) and other researchers also reported beef as the most preferred (Okunlola, 2012; Adetunji and Rauf, 2012; Santos alimi, 2013). Other sources of meat are from the Pigs, Sheeps, Goats, Chikens, Turkeys and rodents (Ahemen et al., 2010; Gambo et al., 2010). Most of these meats are either processed by boiling, frying, drying, smoking and salting. However, reported literatures showed that high prevalence of toxoplasmosis was detected in chickens (Ayinmode and Dubey, 2012), cattle (Joshua and Akinwumi, 2004; Onyiche and Ademola, 2013), pigs (Onyiche and Ademola, 2013; Akande et al., 2016), sheep (Kamani et al., 2010), Goat (Kamani et al., 2010), dogs (Kamani et al., 2010; Ayinmode et al., 2016). Among all the animal types investigated, chickens are most important source of meat in human owing to its high content of protein, phosphorous and other important minerals (Adetunji and Rauf, 2012).
Because the risk of infection with $T$. gondii varies among humans due to cultural differences and the eating habits (Hussain et al., 2017), many human infections would depend on the availability of food, animal of choice, purchase ability and method of meat processing within the study locality. Some prevalence studies conducted in Nigeria reported different seroprevalence of toxoplasmosis associated with consumption of raw or poorly cooked meat. Ishaku et al. (2009) reported that 33.1\% among the seropositive pregnant women have the habits of testing meat while on fire, which means they eat poorly cooked meat. Yusuf et al. (2016) reported $57.4 \%$ of subjects that were seropositive had history of ingestion of poorly cooked meat. However, meat consumption has been reported to be one of the three main mechanisms through which infective stage of the parasite can be transmitted in general population and most common way the pregnant women acquired the infection (Paquet et al., 2013).

\section{Organ Transplant}

Transmission through solid organ transplant is a possibility owing to the parasites ability to invade any nucleated cell. The persistence of the infection depends on the organ affected. Muscle organs were reported to harbour the cyst of the parasite than other organs such as the brain, retina, lungs, kidneys and liver (RobertGangneux and Darde, 2012). When cyst containing organ from the donor, is transplanted to the recipient who had no prior exposure to the infection, such as in heart transplant (Ryining et al.,1979; Michaels et al., 1992), Marrow transplant (Slavin et al., 1994; Medeiros et al., 2001; Escuissato et al., 2004), Liver transplant (Mayes et al., 1995), Small bowel transplant (Campbell et al., 2006), renal transplant (Rogers et al., 2008), an acute and disseminated toxoplasmosis can occur which is often fatal. Organ transplantation has so far gain ground in Nigeria with increasing centers across the country especially for renal, corneal and born marrow transplant for the past 18 years despite challenges in healthcare system (Ulasi and Ijoma 2016; Okafor, 2016). Due to paucity of data on pre and post-transplant preparation and possible complications arising from lack of national registry for such activities, it will be difficult to know if donor and recipients of these organs do undergo T. gondii screening or occurrence of acute toxoplasmosis acquired from the transplant. 


\section{Transmission through Tachyzoite Transplacental Transmission}

This results in transmission from mother to child leading to congenital toxoplasmosis that is characterized by triad of signs including chorioretinitis, intracranial calcification and hydrocephalus (Jones et al., 2001). Primary infection in pregnancy is associated with high risk of obstetric disorder such as abortions, still birth and severe fetal abnormalities. Though most babies infected in utero are delivered with no obvious abnormalities, the infant stand a risk of significant health problems after parturition and later in life (Jones et al., 2001; RobertGangneux and Darde, 2012). However, transplacental transmission, in settings of acute infection, increases with increase in gestational age and the high risk of fetal infection occur in third trimester but the consequences is more pronounced when it occurred in the first trimester (Jones et al., 2001). Those women who had infection before they conceive, do not transmit the parasite to their growing fetuses except in cases of reactivation in settings of immunosuppression (Jones et al., 2001). Prevalence studies estimating the incidence of toxoplasmosis in categories of women such as pregnant women, women in child bearing age and Immunosuppressed women have been reported (Aganga et al., 1990; Onadeko et al., 1996; Olusi et al., 1996; Ishaku et al., 2009; Akinbami et al., 2010; Deji-Agbola et al., 2011; Uttah et al., 2013; Alayande et al., 2013; Nasir et al., 2015; Yusuf et al., 2016; Ballah et al., 2017). Pregnant women especially are vulnerable to infection with $T$. gondii in Nigeria going by the feeding habit, environmental hygiene and a lot of other risk factors associated with the condition. Cases of congenital toxoplasmosis are often scarce or under reported possibly because of the absence or ineffective screening program during antenatal and postnatal visits. Jelliffe (1951) reported the first case of congenital toxoplasmosis in Nigeria and of course from whole African continent. It was detected in a 3 years old boy who presented with loss of milestone and multiple abnormalities such as macrocephaly, radiological evidence of cardiomegaly and intracranial calcification. Both the child and the mother had serological evidence of the infection. More recently however, another case report was published by Amadi et al. (2015) in which they reported in a 17-month-old baby, who was chronically ill-looking, an evidence of congenital toxoplasmosis such as widespread cerebral calcification along with serological evidence of IgG positivity. Cases of congenital toxoplasmosis might have been missed because of inadequate screening program in Nigeria. Despite their vulnerability to infection, prevalence of toxoplasmosis among children is under reported. Children, like adult, do also survive amid various risk factors and often more seen to play in soil, eat unwashed fruits, can play with cat litters and can drink water or poorly cooked meat from unknown source. Thus, children may have the infection acquired from the environmental or transplacental exposure. Study from Lagos state, Southwest Nigeria by Gyang et al. (2015) reported that $24 \%$ of the 382 children consented for the study within the age group of $<12$ years were positive to $T$. gondii infection. Though in this study no much symptom associated with seropositivity except weakness reported, raw meat consumption showed a higher risk of infection on univariate analysis. This study should have a kind of followed up plan on these children for the possible detection of long run complications because most symptoms may present as the child gets older (Pelloux et al., 2003). Apart from this single study, no any study from other parts of the country conducted on children ranging from neonates to under twelve. Studies on pregnant women in Nigeria were reported and some indicate prevalence of T. gondii antibodies in different trimesters. Yusuf et al. (2015) reported that $72.4 \%$ of HIV+ pregnant women studied had IgG antibodies with $\mathrm{CD}^{+}$cells of $<200 / \mu$ l while $10.3 \%$ had $\mathrm{CD}^{+}$of between 200-349 cells/ $\mu$ l though there was no indication of the trimesters for this categories of pregnant women, there is high fetal risk of having congenital toxoplasmosis especially among those with chronic infection with low $\mathrm{CD}^{+}$count that are at risk of reactivation which may be followed by disseminated toxoplasmosis. Nasir et al. (2015) reported that $62.5 \%$ of pregnant women studied were IgM sero-positive while $12.5 \%$ were IgG sero-positive within the first trimester and the reverse is the case in the third trimester. More interestingly however, the study further categorized the seropositive subjects following IgG avidity test. This include $7.2 \%$ of IgM seropositive women had primary infection (IgG-, IgM+ and low IgG avidity), $1.7 \%$ had reactivated infection $(\mathrm{IgG}+, \mathrm{IgM}+$ and high IgG avidity) and $40 \%$ had evidence of previous exposure (IgG+, IgM-). 
Though the study further showed that no significant association between the antibodies and the trimesters, the pregnancy outcome may or may not ended up with complication and the fetus may be at risk of congenital toxoplasmosis. Alayande et al. (2013) reported $30.5 \%$ and $30.7 \%$ of the studied pregnant women were seropositive in first and third trimester respectively. Another recent study reported by Ballah et al. (2017) revealed that 33.5\% pregnant women studied were having higher prevalence of antibodies in second trimester followed by $32.7 \%$ of those in third trimester and in first trimester. These studies did not reveal if the antibodies are indicative of acute onset or chronic exposure, hence making its relevance to congenital toxoplasmosis inconclusive. Ibrahim et al (2017b) reported that of all the pregnant women consented, the prevalence of $43.4 \%$ IgG positivity was obtained and that there is no significant association between the IgG seropositivity and gestational age. Even though the IgG might indicate latent infection, the proimflammatory cytokines assessed were not statistically associated with the IgG positivity as well as gestational age. This however shows that, these group of pregnant women may have immune protection that have controlled the latent form of infection that may result due to pregnancy induce immunosuppression and in them transmission to the fetus is also rare (Robert-Gangneux and Darde, 2012).

\section{Blood and Blood Product}

Transmission through blood and blood product is also a possibility when the donor has acute infection and cases of needle stick injuries have been reported (Robert-Gangneux and Darde, 2012). Prevalence of toxoplasmosis among blood donors have been reported in neighboring African countries. A study conducted by Sirancy et al. (2016), reported that $64.15 \%$ of the respondents were IgG positive while $11.32 \%$ were IgM positive at the time of the study while lower prevalence was reported from Namibia by van der Cof et al. (2014). Though it may not be of significance, but the screening procedure should be encouraged to identify those with possible acute or chronic infection at the time of blood donation. These type of studies among blood donors in Nigeria, as for now are not available in literature.

\section{Sociodemographic Characteristics Associated with Toxoplasmosis Age}

Age plays important role in susceptibility to infection and prevalence of toxoplasmosis has been reported to increase with age where significant differences have been reported between adults and children (El-sheikha, 2008). This may also differ from one country or region to another. Seroprevalence studies showing higher antibodies to $T$. gondii with increasing age have been reported globally (AlvaradoEsquivel et al., 2011). In Nigeria, however, various studies also reported high prevalence among the older population (Kamani et al., 2009; Osunkalu et al., 2011; Alayande et al., 2012; Uttah et al., 2013; Nasir et al., 2015; Yusuf et al., 2015) and in contrast, Ballah et al. (2017) reported $52.86 \%$ sero-positivity among the $<20$ age group than $19.33 \%$ and $8.18 \%$ among the age group 20-39 and those at 40 or above, respectively. Going by the environmental nature of Toxoplasma parasite, its various mode of transmission and availability of its intermediate host in many settings, exposure to this agent can be said to be increasing as human are growing up with or without prior exposure in utero.

\section{Gender}

For sex predilection, this may not be a risk factor for toxoplasmosis because both can share same mode of exposure except if there is genetic preponderance. Although significant differences may be reported from studies between females and males in seropositivity, it may be because females tend to visit hospitals more often than males. Various studies around the globe reported no statistical differences between males and females seropositive to $T$. gondii (Oskouei et al., 2016; Alvarado-Esquivel et al., 2017). However, study from Germany by Wilkin et al. (2016) reported male gender to be a significant risk factor in multivariate analysis. Most studies in Nigeria were conducted on women (women in reproductive age group, pregnant women, immunocompromised) while only few had both male and female participants. James et al. (2013), in a study among individual with mental illness, reported that $60 \%$ of the patient recruited for the study were male but females were significantly more likely to have higher seropositivity than male, though there was no particular risk factor reaches statistical significance, the study should have categorically determined to which risk factor the female population are more exposed to. 
According to Ogoina et al. (2013), 43\% of female that were HIV-positive, were seropositive to $T$. gondii as compared to males $(30.8 \%)$, but this failed to reach significance. Likewise, a study on general population from Northeast Nigeria by Kamani et al. (2011) reported male to have $27.3 \%$ seropositivity than female (19.3\%) which also didn't show any statistical significance. In a stored sera of HIV positive individuals, female had higher rate of seropositivity $(35.3 \%)$ than male $(20 \%)$ according to Alayande et al. (2012). A study by Osunkalu et al. (2011) on HIV-positive individual conducted in Lagos, South West Nigeria reported males to have higher IgG seropositivity $(70.6 \%)$ than female and that was attributed to a possibility of higher rate of meat consumption among male's population.

\section{Area of Residence}

It is a known fact that prevalence of toxoplasmosis differs not only between a wider geographical location, but even within a confined local setting from the capital of a particular state to its neighboring rural areas there could be a significant variability. This has been proven globally (Deniau et al. 1988; Jemum et al., 1998; Robert-Gangneux and Darde 2012; Yan et al., 2016). Inhabitant of rural areas were reported to have likelihood of increase exposure to $T$. gondii infection where as those in the urban cities are more likely to have cyst infection due to increasing urbanization (Lélu et al., 2010). Nasir et al. (2015) reported $54.0 \%$ Seroprevalence among the subjects residing in urban areas than those from rural areas (22.5\%) and this was statistically significant. Same was reported by Kamani et al. (2011) from urban area of Maiduguri.

\section{Occupation}

This may not seem to be related to occurrence of toxoplasmosis, but many occupations related to food substances or their sources, that are likely to be exposed to oocyst or tissue cyst which for instance include fruits, vegetables, meat, chicken that are process by individuals engaged in gardening, farming, poultry services and abattoir working, can be a great source of infection to human. Alvarado-Esquivel et al. (2011) reported lack of association between toxoplasmosis and occupational exposure to raw meat among butchers at 7\% seropositivity and the control at $9 \%$ seropositivity. Even though the number of the control (248) doubles that of the butchers' (124), the sero-positivity did not show any statistical significance. Study on veterinary staff from Canada reported by Shuhaibar et al. (2003) showed that $14.4 \%$ were found to be seropositive and that their occupational exposure to cats does not increase the risk of infection with $T$. gondii. However, study in Nigeria, reported by Alayande et al. (2012) reported that, among the abattoir workers studied, though there were varying Seroprevalence among them based on their eating habits, those that engaged in eating raw meat/suya had 50\% Seroprevalence. Study conducted by Alvarado-Esquivel et al. (2011) reported that consumption of these substances such as unwashed raw fruits and raw meat may be important factors in $T$. gondii infection than mere handling them as per occupation. No available study from Nigeria so far in literature that is purely on farmers, gardeners, fruits and vegetable sellers, hunters and veterinary officials to assess their occupational exposure.

\section{Level of Knowledge and Awareness}

Generally, having some level of literacy, has a greatly impact on health management of an individual. Knowledge on pattern of spread, symptoms and signs of a disease can be of great relevance in knowing how to take preventive measures. Studies across the world were reported to be conducted on healthcare professional and other groups to assess their knowledge and or awareness on toxoplasmosis (Jones et al., 2003; Berriel da Silva et al., 2011; Andiappan et al., 2014; Millar et al., 2014; Pereboom et al., 2015; Efunshile et al., 2017). Majority of these studies on healthcare workers revealed knowledge gaps on toxoplasmosis. A study conducted by Andiappan et al. (2014), on pregnant women from Malaysia, Philippines and Thailand, numbering up to 2598 , only $11 \%$ were aware of toxoplasmosis and only $3.5 \%$ were screened for said infection. Significant number was also reported by Millar et al. (2014) from Brazil to lack awareness on toxoplasmosis. A comprehensive study among healthcare providers was reported by Efunshile et al. (2017) from Nigeria and the result suggested that knowledge gaps on toxoplasmosis exist and this points to inadequate measures on prevention and management of the infection in the country. It is imperative to stress here that; health workers should be attending a continuous education programs on several subjects organized frequently by professional bodies to enhance their skills in patient management and to impart the acquired current knowledge to their patients accordingly. 


\section{Socioeconomic Status}

As it stands to be and according to the American psychological society the socioeconomic status of an individual is a class to which he or she belongs either individually or in group and it reflects the triad of backgrounds comprising of education, occupations and income. The combination of these factors can be used therefore, to assess, measure and determine the socioeconomic status of an individuals or groups which can be high or law (Winkleby et al., 1992; Linda et al., 2015). Socioeconomic status has been evaluated by several researchers on recruited individuals consented for prevalence studies on toxoplasmosis. This is to assess the relationship between the social class of an individual, group or the community to the risk of acquiring infections. Studies reported relate low or high socioeconomic status as risk factors for toxoplasmosis. A low socioeconomic status was found to be associated with high prevalence of T. gondii antibodies (Yasodhara et al., 2004; Alvarado-Esquivel et al., 2011; Siddiqi et al., 2014; Frimpong et al., 2017). In Nigeria, however, different reports of Seroprevalence among the study groups are available in literatures. The triad of education which determines the level of awareness and orientation about the disease, the occupation which may point to occupational exposure as a risk factor and which can further be used to divide the study population into employed or unemployed and the income which is largely determined by one's occupation and which in turn determines one's area of residence (rural or urban) have been reported by several studies in Nigeria to have influence in seroprevalence of toxoplasmosis. Nasir et al., (2015) reported $76.6 \%$ of the respondents that are seropositive had tertiary education compare to those with primary level of education. Despite their level of education, their level of knowledge on the infectious agent, its modes of transmission may be so low, and it is a matter of concern which may need to be addressed through health education and other orientation activities. Same study reported $48.4 \%$ of the respondents resides in the urban areas are seropositive than those residing in the rural areas. The fact that majority attained tertiary education they have tendency of residing in the urban areas particularly to search for suitable employment and several studies point to possibility of high risk of toxoplasmosis within the urban residence population (Linda et al., 2015). More so, the study also showed that respondents that are unemployed have higher rate of $T$. gondii infection than the employed individuals. Several other studies reported data on several factors that indicate socioeconomic status of individual but studies classifying subjects based on their socioeconomic strata are still not reported in Nigeria.

\section{Transmission Prevention}

To date, only a few countries have effective screening policy in existence and are restricted to pregnant women. These countries include the likes of Austria and France, where there was considerable reduction in congenital toxoplasmosis (Jones et al., 2001). However, in countries where there is low incidence of the disease, screening program is not recommended (Pauet et al., 2013) whereas it is strongly recommended in countries with high rate of infection, high incidence of congenital malformations, increased exposure to risk factors and high prevalence of immunosuppressive conditions. Especially for women in reproductive age group, screening program should be instituted at pre-conception period and pre-natal period to have reduced fetal sequalae if appropriate measure is adopted as well as post-natal period, which may also reduce the clinical severity (Robert-Gangneux and Darde, 2012). Screening is greatly recommended for immunocompromised individuals because of the possibilities of having reactivation of latent infection that would result in fatal toxoplasma encephalitis. Though it may exist in the national policy, screening program in Nigeria for toxoplasmosis may not be as common as other infectious disease like HIV and Hepatitis B infection especially during antenatal screening. Such dearth of information on its availability or absence of the entire program may be backed by such challenges as the cost and sensitivity of the procedures. Considering the risk factors therein and results from Seroprevalence studies, at least, the screening program should be in place and accessible to even the vulnerable groups; pregnant women and immunocompromised population. This measure will reduce the financial and social burden of disease aftermath when appropriate treatment is instituted after screening.

Furthermore, considering the various ways through which this infection can be acquired, prevention of its occurrence would rather take a multidimensional approach. Several authors put forward recommendations through which primary infection can be prevented. 
Most of these recommendations rally round health education, proper hygienic measures, and efficient food processing before consumption.

\section{Health Education}

Health education and general awareness offer a significant contribution in infection prevention and still retain a significant impact when it comes to how to prevent the occurrence, manage and control infection especially among the at-risk population. Educating people on how the infection is acquired and spread will greatly result in decrease incidence. On the other hand, general awareness on toxoplasmosis among Nigerians is lacking more interestingly among the healthcare givers as reported recently by Efunshile et al. (2017). Should there be proper awareness among the populace with emphasis on how to get rid of risky behaviors, low infection rate will result. Such measures were proven positive in the past surveys (Jones et al., 2001).

\section{Proper Hygiene}

Again, due to its nature of spread, proper hygiene, be it personal or general, if carefully observed, will reduce occurrence of toxoplasmosis especially among the vulnerable groups. Topping the list as usual is proper hand washing. Hand washing if properly conducted especially after any prior exposure to cat faeces, cat litters or box, soil contaminated with cat faeces, gardening and other outdoor activities, will sure results in reduced incidence of primary infection. Handling of cat litters should be with utmost care and if need be, wearing hand gloves should be made compulsory. When disposing cat faeces, which should be away from area of contact and water body, it should not be used as local manures in gardens and farms at all costs because of its potential risk of spreading the oocyst. If possible, such fecal matters can be exposed to a temperature level of up to $60^{\circ} \mathrm{C}$ for some couple of minutes enough to kill the oocyst therein (Robert-Gangneux and Darde, 2012).

\section{REFER |ENCES}

Adetunji, M. O., and Rauf, M. O. (2012): Analysis of household demand for meat. Southwest, Nigeria. Global Journal of Science Frontier Research Agriculture and Biology GJSFR, 12(1).

Afonso, E., Thulliez, P., and Gilot-Fromont, E. (2010): Local meteorological conditions, dynamics of seroconversion to Toxoplasma gondii in cats (Felis catus) and oocyst burden in a rural

\section{Proper Food Processing}

Because of the environmental influence in transmission of T. gondii, contamination of food substances leads to food borne toxoplasmosis which is rated in United State as the second most common cause of death from food borne infections (Jones et al., 2014). Therefore, proper food processing and proper feeding habit will halt transmission of this infection. It is thus recommended that environmental oocyst and the tissue cyst stage in meat should be properly handled by adequate processing of any potential food substance for consumption. Use of unfiltered water for drinking, washing of fruits or vegetable and hand washing, sourced from surface water body or any unprotected source should be discouraged. Preparation of food for consumption should be given serious attention. Meat which harbors the cystic stage is hazardous and can cause acute infection if not thoroughly processed and washed, poorly cooked or even consumed raw.

\section{Conclusion}

With an overall prevalence of 32\% (Ohiolei and Isaac, 2016), toxoplasmosis is under reported in Nigeria with a low level of awareness even among the health care workers.

\section{Recommendation}

We recommend for an encompassing epidemiological survey of toxoplasmosis in Nigeria. Also, an efficient routine screening and diagnostic programs should be instituted, targeting vulnerable groups such as pregnant women, women of child bearing age, neonates, children, occupationally exposed and immunocompromised individuals.

\section{Authors contribution}

SAA, YMA conceived the study, SAA, YMA and GMI conducted the literature search, SAA and $\mathrm{YH}$ wrote the manuscript, YMA, YH, AM, WMN, $B J A$ and $Y I$ reviewed the manuscript.

\section{Conflicts of interest}

The authors declare that there are no conflicts of interest.

environment. Epidemiology

and Infection, 138(8), 1105-1113.

Aganga, A. O., Umoh, J. U., Ekwempu, C. C., \& Kyewalabye, E. K. (1990). Prevalence studies of human Toxoplasma infection in Zaria, Nigeria. Nigerian Journal of Parasitology, 159- 164.

Ahemen, T., and Zahraddeen, D. (2010). Species contribution as source of meat and their foetal wastage in Taraba State, Nigeria. Archives of Applied Science Research, 2(5), 85-91. 
Ajmal, A., Maqbool, A., Qamar, M. F., Ashraf, K., and Anjum, A. A. (2013): Detection of Toxoplasma gondii in environmental matrices (water, soil, fruits and vegetables). African Journal of Microbiology Research, $7(16), \quad 1505-$ 1511.

Akande, F. A., Olayemi, M. D., Ajayi, O. L., Oni, O. O., and Akinkuotu, O. A. (2016): Sero-prevalence of swine toxoplasmosis in Ogun State, Nigeria. Nigerian Journal of Parasitology, 37(2), 195-199.

Akinbami, A. A., Adewunmi, A. A., Rabiu, K. A., Wright, K. O., Dosunmu, A. O., Dada, M. O., and Adeyemo, T. A. (2010): Seroprevalence of Toxoplasma gondii antibodies amongst pregnant women at the Lagos State University Teaching Hospital, Nigeria. The Nigerian postgraduate medical journal, 17(2), 164-167.

Alayande, M. O., Edungbola, L. D., Fabiyi, J. P., Faleke, O. O., Awosan, K. J., Fadeyi, A., and Suleiman, N. (2012): Seroprevalence of Toxoplasma gondii infection among abattoir workers in Sokoto, Nigeria. Sahel Medical Journal, 15(2), 80.

Alvarado-Esquivel, C., Estrada-Martínez, S., and Liesenfeld, O. (2011): Toxoplasma gondii infection in workers occupationally exposed to unwashed raw fruits and vegetables: a case control seroprevalence study. Parasites and vectors, 4(1), 235.

Alvarado-Esquivel, C., Liesenfeld, O., EstradaMartínez, S., and and Félix-Huerta, J. (2011). Toxoplasma gondii infection in workers occupationally exposed to raw meat. Occupational medicine, 61(4), 265-269.

Alvarado-Esquivel, C., Loera-Moncivais, N., Hernandez-Tinoco, J., SanchezAnguiano, L. F., Hernandez-Madrid, G., Rabago-Sanchez, E., and AntunaSalcido, E. I. (2017): Lack of Association between Toxoplasma gondii Infection and Diabetes Mellitus: A Matched Case-Control Study in a Mexican Population. Journal of clinical medicine research, 9(6), 508.

Amadi, O., Ndu, I., Chinawa, J., Jean, N., and Obidi, N. (2015): Toxoplasmosis in a 17month-old Nigerian: A case report. Annals of Tropical Medicine and Public Health, 8(3), 64.
Andiappan, H., Nissapatorn, V., Sawangjaroen, N., Khaing, S. L., Salibay, C. C., Cheung, M. M. M., and Mat Adenan, N. A. (2014): Knowledge and practice on Toxoplasma infection in pregnant women from Malaysia, Philippines, and Thailand. Frontiers in microbiology, 5, 291.

Aramini, J. J., Stephen, C., Dubey, J. P., Engelstoft, C., Schwantje, H., and Ribble, C. S. (1999): Potential contamination of drinking water with Toxoplasma gondii oocysts. Epidemiology and Infection, 122(2), 305-315.

Ayinmode, A. B., Ishola, O. O., and Oderinu, T. A. (2015): Seroprevalence of Toxoplasma gondii in dogs slaughtered for food in Southwestern Nigeria and assessment of consumer's knowledge and behavior. Alexandria Journal of Veterinary Sciences, 45, 161165.

Ayinmode, A.B and Dubey J.P (2012): Toxoplasma gondii Infection in FreeRange Chicken: Mini-Review and Seroprevalence Study in Oyo State, Nigeria. Afr. J. Biomed. Res. 15; 145 $-148$.

Ballah, F. M., Maikai, B. V., Magaji, A. A., Shuaibu, A. B., El-Nafaty, A. U., Sambo, Y. T., and Suleiman, F (2017): Seroprevalence and Risk of Toxoplasma gondii Infection among Pregnant Women at Federal Teaching Hospital Gombe, Nigeria. Asian Journal of Medicine and Health 3(2): 1-5

Bénard, C., Bonnet, B., andand Guivert, B. (2010): Demand for farm animal products in Nigeria: An opportunity for Sahel countries. Grain de Sel, 51, 1415.

Bobola O. M, Mafimisebi T. E, Ikuemonisan E. S. (2015): Price Fluctuations, Linkages and Causality in the Nigerian Beef Market. $J$ Fisheries Livest Prod 3: 135. doi:10.4172/2332-2608.1000135

Campbell, A. L., Goldberg, C. L., Magid, M. S., Gondolesi, G., Rumbo, C., andand Herold, B. C. (2006): First case of toxoplasmosis following small bowel transplantation and systematic review of tissue-invasive toxoplasmosis following non-cardiac solid organ transplantation. Transplantation, 81(3), 408-417. 
De Moura, L., Bahia-Oliveira, L. M. G., Wada, M. Y., Jones, J. L., Tuboi, S. H., Carmo, E. H., and Da Silva, A. J. (2006): Waterborne toxoplasmosis, Brazil, from field to gene. Emerging infectious diseases, 12(2), 326.

Deji-Agboola, A. M., Busari, O. S., Osinupebi, O. A., and Amoo, A. O. J. (2011): International Journal of Biological and Medical Research. (IJB M R), 2(4), 11351139.

Deniau, M., Tourte-Schaefer, C., Agbo, K., Dupouy-Camet, J., Heyer, C., and Lapierre, J. (1991): Evaluation of the risk of congenital toxoplasmosis in Togo. Bulletin de la Societe de pathologie exotique (1990), 84(5 Pt 5), 664-672.

Dos Santos, T. R., Nunes, C. M., Luvizotto, M. C. R., de Moura, A. B., Lopes, W. D. Z., da Costa, A. J., and Bresciani, K. D. S. (2010): Detection of Toxoplasma gondii oocysts in environmental samples from public schools. Veterinary parasitology, 171(1-2), 53-57.

Dubey, J. P., \& Beattie, C. P. (1988). Toxoplasmosis of animals and man. CRC Press, Inc.

Dubey, J.P., Lindsay, D.S., Speer, C.A. (1990). Structures of Toxoplasma gondii tachyzoites, bradyzoites, and sporozoites and biology and development of tissue cysts. Clinical Microbiology Reviews. 11: 267-299

Dumetre A and Darde ML. (2003). How to detect Toxoplasma gondii oocysts in environmental samples? FEMS Microbiol. Rev. 27:651-661.

Dumètre, A., and Dardé, M. L. (2003): How to detect Toxoplasma gondii oocysts in environmental samples. FEMS Microbiology Reviews, 275), 651-661.

Efunshile, A. M., Elikwu, C. J., and Jokelainen, P. (2017): Toxoplasmosis-Awareness and knowledge among medical doctors in Nigeria. PloS one, 12(12), e0189709.

Elsheikha, H. M. (2008): Congenital toxoplasmosis: priorities for further health promotion action. Public health, 122(4), 335-353.

Escuissato, D. L., de Aguiar, R. O., Gasparetto, E. L., and Müller, N. L. (2004):
Disseminated toxoplasmosis after bone marrow transplantation: high-resolution CT appearance. Journal of thoracic imaging, 19(3), 207-209.

Foroutan, M., \& Ghaffarifar, F. (2018). Calciumdependent protein kinases are potential targets for Toxoplasma gondii vaccine. Clinical and experimental vaccine research, $\lambda(1), 24-36$.

Frimpong, C., Makasa, M., Sitali, L., and Michelo, C. (2017): Seroprevalence and determinants of toxoplasmosis in pregnant women attending antenatal clinic at the university teaching hospital, Lusaka, Zambia. BMC infectious diseases, 1入(1), 10.

Gambo, B. G., Raufu, I. A., and Ambali, A. G. (2010): Residents in Borno State and their meat preference among ruminant species. African Journal of General Agriculture, 6(2), 53-58.

Giegbefumwen, O. A, Ajogi, I., Okolocha, E.C., George, B., Jonathan, D. (2013): Seroprevalence of Toxoplasma gondii Antibodies in Pigs at Slaughter in Kafanchan and Kaduna, Kaduna State, Nigeria. Journal of Science (JOS) 3(2): 277-281.

Guo, M., Dubey, J. P., Hill, D., Buchanan, R. L., Gamble, H. R., Jones, J. L., and Pradhan, A. K. (2015): Prevalence and risk factors for Toxoplasma gondii infection in meat animals and meat products destined for human consumption. Journal of food protection, 78(2), 457- 476.

Gyang, V. P., Akinwale, O. P., Lee, Y. L., Chuang, T. W., Orok, A., Ajibaye, O., and Fan, K.H. (2015): Toxoplasma gondii infection: seroprevalence and associated risk factors among primary schoolchildren in Lagos City, Southern Nigeria. Revista da Sociedade Brasileira de Medicina Tropical, 48(1), 56-63.

Hill, D., and Dubey, J. P. (2002): Toxoplasma gondii: transmission, diagnosis and prevention. Clinical microbiology and infection, 8(10), 634-640.

Hussain, M. A., Stitt, V., Szabo, E. A., \& Nelan, B. (2017). Toxoplasma gondii in the Food Supply. Pathogens, 6(2), 21. 
Ibrahim, A., Kumurya, A. S., Muhammad, A.B., Adamu, A. I., Shema, F. B., Sule, H., Yahaya, H., Koki, A. Y., Ado, B. K., Sulaiman, M. A., and Aminu, M. A (2017b): Anti-toxoplasma IgG seropositivity and T-cell mediated immune responses among pregnant women in Kano, Nigeria. BJMLS, 2(1): $227-236$

Ibrahim, A., Kumurya, A. S., Yahaya, H., Abdu, A., Ado, B. K., Ella, E. E., Suleiman, A. B., Sulaiman, M. A., Aminu, M. A. and Koki, A. Y. (2017a): T-Cell Mediated Immune Responses in Obstetric Population Acutely Infected with Toxoplasmosis in Kano, Nigeria. UJMR, 2(1): $217-227$.

Ishaku, B., Ajogi, I., Umoh, J. U., Lawal, I., and Randawa, A. J. (2009): Seroprevalence and risk factors for Toxoplasma gondii infection among antenatal women in Zaria, Nigeria. Res $J$ Med Med Sci, 4(2), 483-488.

James, B. O., Agbonile, I. O., Okolo, M., Lawani, A. O., and Omoaregba, J. O. (2013): Prevalence of Toxoplasma gondii infection among individuals with severe mental illness in Nigeria: a case control study. Pathogens and global health, 1074), 189-193.

Jasper, J. T., Nguyen, M. T., Jones, Z. L., Ismail, N. S., Sedlak, D. L., Sharp, J. O., and Nelson, K. L. (2013): Unit process wetlands for removal of trace organic contaminants and pathogens from municipal

effluents. Environmental engineering science, 30(8), 421-436.

Jelliffe, D. B. (1951): Congenital toxoplasmosis in an African child. Archives of disease in childhood, 26(127), 258.

Jones, J. L., Lopez, A., Wilson, M., Schulkin, J., and Gibbs, R. (2001): Congenital toxoplasmosis: a review. Obstetrical andand gynecological survey, 56(5), 296-305.

Jones, J. L., Ogunmodede, F., Scheftel, J., Kirkland, E., Lopez, A., Schulkin, J. and Lynfield, $\mathrm{R}$.

(2003): Toxoplasmosis-related knowledge and practices among pregnant women in the United States. Infectious diseases in obstetrics and gynecology, 11(3), 139145.

Jones, J. L., Parise, M. E., and Fiore, A. E. (2014). Neglected parasitic infections in the United States: toxoplasmosis. The American journal of Tropical Medicine and Hygiene, 90(5), 794-799.

Joshua, R.A. and Akinwumi, K.A. (2004): Prevalence of antibodies to Toxoplasma gondii in four breeds of cattle at Ibadan, Nigeria. Trop. Vet., 21(3): 134-137.

Kamani, J., Mani, A. U., and Egwu, G. O. (2010): Seroprevalence of Toxoplasma gondii infection in domestic sheep and goats in Borno state, Nigeria. Tropical Animal Health and Production, 42(4), 793-797.

Kamani, J., Mani, A. U., Egwu, G. O., and Kumshe, H. A. (2009): Seroprevalence of human infection with Toxoplasma gondii and the associated risk factors, in Maiduguri, Borno state, Nigeria. Annals of Tropical Medicine and Parasitology, 103(4), 317-321.

Lélu, M., Langlais, M., Poulle, M. L., andand Gilot-Fromont, E. (2010): Transmission dynamics of Toxoplasma gondii along an urban-rural gradient. Theoretical population biology, 78(2), 139-147.

Mayes, J. T., O'Connor, B. J., Avery, R., Castellani, W., andand Carey, W. (1995): Transmission of Toxoplasma gondii infection by liver transplantation. Clinical infectious diseases, 21(3):511-515.

Medeiros, B. C., Medeiros, C. R., Werner, B., Loddo, G., Pasquini, R., andand Bleggi-Torres, L. F. (2001). Disseminated toxoplasmosis after bone marrow transplantation: report of 9 cases. Transplant infectious disease, 3(1), 24-28.

Meerburg, B. G., and Kijlstra, A. (2009). Changing climate-changing pathogens: Toxoplasma gondii in North-Western Europe. Parasitology research, 105(1), 1724.

Michaels, M. G., Wald, E. R., Fricker, F. J., del Nido, P. J., andand Armitage, J. (1992). Toxoplasmosis in pediatric recipients of heart transplants. Clinical infectious diseases, 14(4), 847-851.

Millar, P. R., Moura, F. L. D., Bastos, O. M. P., Mattos, D. P. B. G. D., Fonseca, A. B. M., Sudré, A. P., and Amendoeira, M. R. R. (2014): Toxoplasmosis-related knowledge among pregnant and postpartum women attended in public health units in Niterói, Rio de Janeiro, Brazil. Revista do Instituto de Medicina Tropical de São Paulo, 56(5), 433-438. 
Nasir, I. A., Aderinsayo, A. H., Mele, H. U., and Aliyu, M. M. (2015): Prevalence and associated risk factors of Toxoplasma gondii antibodies among pregnant women attending Maiduguri teaching hospital, Nigeria. Journal of Medical Sciences, 15(3), 147.

Oboro, I. L., Obunge, O. K., and Wariso, K. T. (2016): Sero-epidemiology of Toxoplasmosis among pregnant women in the University of Port Harcourt Teaching Hospital, Nigeria. Nigerian Health Journal, 16(1).

Ogoina, D., Onyemelukwe, G. C., Musa, B. O., andand Obiako, R. O. (2013): Seroprevalence of IgM and IgG antibodies to Toxoplasma infection in healthy and HIV-positive adults from Northern Nigeria. The Journal of Infection in Developing Countries, 7(05), 398-403.

Ohiolei, J. A., and Isaac, C. (2016): Toxoplasmosis in Nigeria: the story so far (1950-2016): a review. Folia Parasitol, 63.030

Okafor, U. H. (2016): Kidney transplant in Nigeria: a single centre experience. The Pan African Medical Journal, 25.

Okunlola, O. O. (2012): Meat Preference and Meat Consumption Pattern of Southwestern Nigeria: A Study of Sandwich Degree Students of Ekiti State University, Ado-Ekiti, Oyo Study Centre. Journal of Agriculture, Forestry and the Social Sciences, 10(1), 23-31.

Okwuzu, J. O., Odunukwe, N. N., Ezechi, O. C., Gbajabiamila, T. A., Musa, A. Z., Ezeobi, P. M. and Adetunji, M. A. (2014): Toxoplasma gondii infection in HIV/AIDS: prevalence and risk factors. African Journal of Clinical and Experimental Microbiology, 15(2), 97102.

Olusi, T., Grob, U., \& Ajayi, J. (1996). High incidence of toxoplasmosis during pregnancy in Nigeria. Scandinavian journal of infectious diseases, 28(6), 645-646.
Onadeko, M. O., Joynson, D. H., Payne, R. A., \& Francis, J. (1996). The prevalence of toxoplasma antibodies in pregnant Nigerian women and the occurrence of stillbirth and congenital malformation. African journal of medicine and medical sciences, 25(4), 331- 334.

Onyiche, T. E., and Ademola, I. O. (2015): Seroprevalence of anti-Toxoplasma gondii antibodies in cattle and pigs in Ibadan, Nigeria. Journal of Parasitic Diseases, 39(2), 309-314.

Oskouei, M. M., Hamidi, F., Talebi, M., Farhoudi, M., Taheraghdam, A. A., Kazemi, T. and Fallah, E. (2016): The correlation between Toxoplasma gondii infection and Parkinson's disease: a case-control study. Journal of Parasitic Diseases, 40(3), 872-876.

Osunkalu, V. O., Akanmu, S. A., Ofomah, N. J., Onyiaorah, I. V., Adediran, A. A., Akinde, R. O., and Onwuezobe, I. A. (2011): Seroprevalence of Toxoplasma gondii IgG antibody in HIVinfected patients at the Lagos University Teaching Hospital. HIV/AIDS (Auckland, NZ), 3, 101.

Oyinloye, S. O., Igila-Atsibee, M., Ajayi, B., \& Lawan, M. A. (2014). Serological screening for ante-natal toxoplasmosis in Maiduguri municipal council, Borno state, Nigeria. African Journal of Clinical and Experimental Microbiology, 15(2), 91-96.

Paquet, C., Yudin, M. H., Allen, V. M., Bouchard, C., Boucher, M., Caddy, S. and Van Schalkwyk, J. (2013): Toxoplasmosis in pregnancy: prevention, screening, and treatment. Journal of obstetrics and gynaecology Canada, 35(1), 78-79.

Pelloux, H., Brenier-Pinchart, M. P., andand Fricker-Hidalgo, H. (2003): Protozoan infections in humans: congenital toxoplasmosis. European journal of protistology, 39(4), 444-448.

Pereboom, M. T., Manniën, J., Spelten, E. R., Schellevis, F. G., and and Hutton, E. K. (2013):Observational study to assess pregnant women's knowledge and behaviour to prevent toxoplasmosis, listeriosis and cytomegalovirus. BMC pregnancy and childbirth, 13(1): 98. 
Robert-Gangneux, F., and Dardé, M. L. (2012). Epidemiology of and diagnostic

Rogers, N. M., Peh, C. A., Faull, R., Pannell, M., Cooper, J., andand Russ, G. R. (2008):Transmission of toxoplasmosis in two renal allograft recipients receiving an organ from the same donor. Transplant Infectious Disease, 10(1), 71-74.

Ryning, F. W., McLEOD, R. I. M. A., Maddox, J. C., Hunt, S. H. A. R. O. N. and Remington, J.S. (1979). Probable transmission of Toxoplasma gondii by organ transplantation. Ann Intern Med, 90(1), 47-9.

Shapiro, K., Miller, M., and Mazet, J. (2012): Temporal association between landbased runoff events and California sea otter (Enhydra lutris nereis) protozoal mortalities. Journal of Wildlife Diseases, 48(2), 394-404.

Sharif, M., Daryani, A., Barzegar, G., and Nasrolahei, M. (2010): A seroepidemiological survey for toxoplasmosis among schoolchildren of Sari, Northern Iran. Trop Biomed, 27(2), 220- 5.

Shuhaiber, S., Koren, G., Boskovic, R., Einarson, T. R., Soldin, O. P., andand Einarson, A. (2003). Seroprevalence of Toxoplasma gondii infection among veterinary staff in Ontario, Canada (2002): implications for teratogenic risk. BMC infectious diseases, 3(1), 8.

Siddiqui, N., Shujatullah, F., Khan, H. M., Rabbani, T., andand Khan, P. A. (2014): Socioeconomic status and prevalence of toxoplasmosis in pregnant women with bad obstetric history. J Immunol Vaccine Technol, 1(1), 101-103.

Siransy, L., Dasse, S. R., Dou Gonat, S. P., Legbedji, A., N'guessan, K., Kouacou, P. A and Menan, H. (2016): Immunity Status of Blood Donors Regarding Toxoplasma gondii Infection in a Low-Income District of Abidjan, Côte d'Ivoire, West Africa. Journal of immunology research, 2016.

Slavin, M. A., Meyers, J. D., Remington, J. S., and Hackman, R. C. (1994): Toxoplasma gondii infection in marrow transplant recipients: a 20 year experience. Bone marrow transplantation, 13(5), 549-557. strategies for toxoplasmosis. Clinical microbiology reviews, 25(2), 264-296.

Sroka, J., Wójcik-Fatla, A., Szymanska, J., Dutkiewicz, J., Zajac, V., and Zwolinski, J. (2010): The occurrence of Toxoplasma gondii infection in people and animals from rural environment of Lublin region-estimate of potential role of water as a source of infection. Annals of Agricultural and Environmental Medicine, 1入 1), 125-132.

ThankGod Emmanuel Onyiche and Isaiah Oluwafemi Ademola (2013):

Seroprevalence of anti-Toxoplasma gondii antibodies in cattle and pigs in Ibadan, Nigeria. J Parasit Dis (Apr-June 2015) 39(2):309-314.

Titus Olusi, Uwe Grob and Jerry Ajayi (1996): High Incidence of Toxoplasmosis during pregnancy in Nigeria. Scandinavian Journal of Infectious Diseases; 289 (6).

Ulasi, I. I., andand Ijoma, C. K. (2016): Organ transplantation Nigeria. Transplantation, 100(4), 695697.

Uttah, E., Ogban, E., and Okonofua, C. (2013): Toxoplasmosis: A global infection, so widespread, so neglected. IJSRP, 3, 1-6.

Van der Colf, B. E., and and Noden, B. H. (2014): Low seroprevalence of antibodies to Toxoplasma gondii in blood donors in central Namibia. Southern African Journal of Infectious Diseases, 29(3), 101-104.

Villena, I., Aubert, D., Gomis, P., Ferté, H., Inglard, J. C., Denis-Bisiaux, $\mathrm{H}$ and Pinon, J. M. (2004). Evaluation of a strategy for Toxoplasma gondii oocyst detection in water. Applied and Environmental Microbiology, 70(7), 4035-4039.

Weigel RM, Dubey JP, Dyer D, Siegel AM. (1999). Risk factors for infection with Toxoplasma gondii for residents and workers on swine farms in Illinois. American Journal of Tropical Medicine and Hygiene; 60: 793-8.

Wilking, H., Thamm, M., Stark, K., Aebischer, T., and Seeber, F. (2016): Prevalence, incidence estimations, and risk factors of Toxoplasma gondii infection in Germany: a representative, cross-sectional, serological study. Scientific reports, 6, 22551. 
Winkleby, M. A., Jatulis, D. E., Frank, E., and Fortmann, S. P. (1992): Socioeconomic status and health: how education, income, and occupation contribute to risk factors for cardiovascular disease. American Journal of public health, 82(6), 816-820.

Winters-Miner L, A., P.S. Bolding, J.M. Hilbe, M. Goldstein, T. Hill, R. Nisbet, N. Walton, G.D. Miner. (2015): Personalized Medicine. Academic press; Published by Elsevier Inc pp176-204.

Yan, C., Liang, L. J., Zheng, K. Y., and Zhu, X. Q. (2016): Impact of environmental factors on the emergence, transmission and distribution of Toxoplasma gondii. Parasites and vectors, 9(1), 137.

Yasodhara, P., Ramalakshmi, B. A., Lakshmi, V., and Krishna, T. P. (2004): Socioeconomic status and prevalence of toxoplasmosis during pregnancy. Indian Journal of medical microbiology, 22(4): 241.
Yohanes, T., Zerdo, Z., Chufamo, N. and Abossie, A. (2017): Toxoplasma gondii Infection: Seroprevalence and associated Factors among Pregnant Women Attending in Antenatal Clinic of Arba Minch Hospital, South Ethiopia: Cross Sectional Study. Trans/ Biomed, 8:1. doi: 10.2167/2172-0479.1000105.

Yusuf A.M., Yahaya S., Azeez-Akande O. (2016): Seroprevalence and risk factors of Toxoplasma gondii infection (toxoplasmosis) among HIV seropositive pregnant women in a tertiary healthcare centre, Kano, Northern Nigeria. J. Med. Med. Sci. 7: 001-005. 